\title{
Comparison of pre treatment with Ondansetron and Lignocaine over Pain on Etomidate Injection. A double blind prospective non randomised study
}

\author{
Abid Banavasi ${ }^{1}$, Thippeswamy $\mathrm{H} \mathrm{G}^{2}$, Sampathila Padmanabha Bhat ${ }^{3}$. \\ ${ }^{I}$ Post Graduate, Department of Anaesthesiology, Yenepoya Medical College, Mangalore, India. \\ ${ }^{2}$ Assistant Professor, Department of Anaesthesiology, Yenepoya Medical College, Mangalore, India. \\ ${ }^{3}$ Professor and Head, Department of Anaesthesiology, Yenepoya Medical College, Mangalore, India
}

\begin{abstract}
:
Background: Etomidate is the preferred induction agent in patient with Cardiac disease due to its cardiac vascular stability. It can cause severe pain during IV administration which can produce increased stress response. Various methods have been tried to reduce the pain of etomidate injection with variable success. Lignocaine pre-treatment which is extensively used to reduce the pain of propofol injection is also used to reduce the pain of etomidate injection.

Materials And Methods: This nonrandomised double blind, study was done after getting ethical clearance from university ethical committee. After informed consent 40 patients of both sexes aged between 18 to 65 years of ASA physical status 1, 2 \& 3, who were posted for various elective surgical procedure planned under general anaesthesia were enrolled for the study.. They were not given any premedication. On arriving to Operating room (OR) 20G IV cannula inserted on dorsum of both hands and both flushed with100ml of normal saline. Venous drainage was occluded with elastic band in the both hands at midarm. In one hand $2 \mathrm{ml}$ of $1 \%$ lignocaine followed by $1 \mathrm{ml}(2 \mathrm{mg}$ ) of Etomidate is Injected and pain is assessed by Verbal rating scale(VRS). After one minute in other hand $2 \mathrm{ml}(8 \mathrm{mg})$ ondansetron injected followed by $1 \mathrm{ml}(2 \mathrm{mg})$ of Etomidate and pain is assessed.

Statistical analysis: Non-Parametric test-Wilcoxon Sign Ranks Test is used to compare both drugs .Analysis is perfomed using SPSS Version22.

Results: A total number of 40 patients (male $=57.50 \%$, female $=42.50 \%$ ). The mean age of patient was 42.85 , The mean VRS pain score of etomidate after pre-administration of intravenous lignocaine (Drug A) was 1.58, which was lower compared to pre-administration of ondansetron(Drug )2.43.

Conclusion: This study illustrates that pre-treatment with intravenous lignocaine significantly reduces the pain on injection of etomidate compare to ondansetron. (P value $<0.001)$.

Keywords: Etomidate; Lignocaine; Ondansetron; Pain on injection.Verbal rating scale.

\section{I "Introduction"}

Various agents have been used for intravenous induction of anesthesia. Etomidate is one of the popular new intravenous anesthetic agent, which can be administered during induction of general anaesthesia or sedation for short procedure. Etomidate is a hypnotic drug without analgesic property[1-3]. The intravenous administration of up to $0.6 \mathrm{mg} / \mathrm{kg}$ of Etomidate to patients with severe cardiovascular disease has little or no effect on myocardial metabolism, cardiac output, peripheral circulation or pulmonary circulation[5-7]. Etomidate is rapidly metabolised in the liver. Etomidate injection has pain on injection as an unpleasant adverse effects of this drug. Propylene glycol formulated in etomidate may damage vascular endothelium and produce pain[17-19]. Several techniques and drugs have been proposed over the years to reduce the incidence and severity of such pain $[4,16]$. The aim of the present prospective non randomised controlled single-centre double blind study was to compare the incidence of pain on injection with Etomidate with pre treatment of ondansetron and lignocaine.
\end{abstract}

\section{Methodology}

Forty patients posted for elective surgery requiring general anesthesia were included in the study. Patients of either gender between age of 18 and 65 years belonging to American Society of Anesthesiologist (ASA) Physical Status 1, 2, and 3 were included in the study. Exclusion criteria were Patient refusal, ASA status $4 \& 5$, emergency surgeries, patients suffering from neuromuscular disorders, peripheral vascular disease, hypothyroidism, history of cardiopulmonary disease, psychological disease and diabetes mellitus. If patients have history of allergic response to either, Etomidate or 5HT3 receptor antagonist, and patients who received any analgesic or sedative drugs during the previous 24hours prior to surgery were excluded from the study. 
Selected patients were not given any premedication. On arriving to Operating room (OR) 20G IV cannula inserted on dorsum of both hands and both flushed with $100 \mathrm{ml}$ of normal saline. Venous drainage was occluded with elastic band in the both hands at midarm. The syringes were loaded and labelled A \& B, both will have equal volumes of drug $2 \mathrm{ml} \&$ in same quantity of syringes $(2 \mathrm{ml})$, Syringes are handed over to anaesthetist who is administering the drug. The observer as well as the patient is blinded for the content of the syringes. Observer will evaluate pain score by Verbal rating score (VRS). The Anesthetist will administer drug in the right hand side cannula over 30 seconds and elastic band is removed. After one minute drug B is administered in the other hand followed by one $\mathrm{ml}$ of Etomidate Injection. VRS is assessed by the Observer. The person who loaded the drug knows about drug Label A \& B will interpret with data (result). Then patents were induced with etomidate with $0.3 \mathrm{mg} / \mathrm{kg}$ dosage, $1 \mathrm{ml}$ of etomidate=2mg. Before injection Drugs, Hemodynamic parameters (Heart rate, Non invasive Blood Pressure, SPO2) are noted, and after completion of procedure, Hemodynamic parameters are recorded. Recovery from anaesthesia was recorded as the time taken from the end of operation to the patient opening his eyes on command. The patient remained in the recovery ward for at least two hour postoperatively. Assessments: Pain was measured using verbal rating scale, Pain score (0: no pain, 1:mild pain, 2:moderate pain, 3:severe pain, 4:extreme pain). The assessments were based on the patient's response during the injection of the study drug.

\section{Ethical}

Study was started after getting ethical clearance committee and procedures followed were in accordance with the Ethical Standards of Yenepoya University Ethics Committee.

\section{Statistical analysis}

Wilcoxon sign rank test is used to compare both drugs. Analysis is performed using SPSS Version 22.

\section{Results}

The age weight and ASA physical status are presented in table1. A total number of 40 patients (male $=57.50 \%$, female $=42.50 \%$ ). The mean age of patients was 42.85, The preoperative BP, HR, SPO2 scores are reported as (Mean $\pm \mathrm{SD}$ ). The mean of pain score of etomidate after pre-administration of intravenous

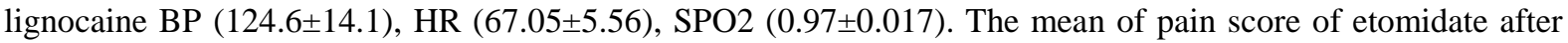
post-administration of intravenous lignocaine BP $(125.25 \pm 14.32), \operatorname{HR}(72.5 \pm 6.51), \operatorname{SPO} 2(0.97 \pm 0.014)$. There was transient rise in heart rate in patients suffering from pain of verbal rating scale(VRS) score 2-3 in both the labelled drugs, but no changes in blood pressure were noted. After etomidate injection no significant excitatory signs like hypertension, spontaneous movements twitching, tremor and respiratory effects like cough hiccup and laryngospasm were noted. There is significant difference between ondansetron and lignocaine on prevention of injection pain caused by etomidate during induction of anesthesia $(\mathrm{P}$ value $<0.01)$

Table1: Table showing frequency distribution of gender

\begin{tabular}{|l|l|}
\hline \multicolumn{2}{|l|}{ Frequency $(\%)$} \\
\hline Female & $17(42.5)$ \\
\hline Male & $23(57.5)$ \\
\hline Total & $40(100)$ \\
\hline
\end{tabular}

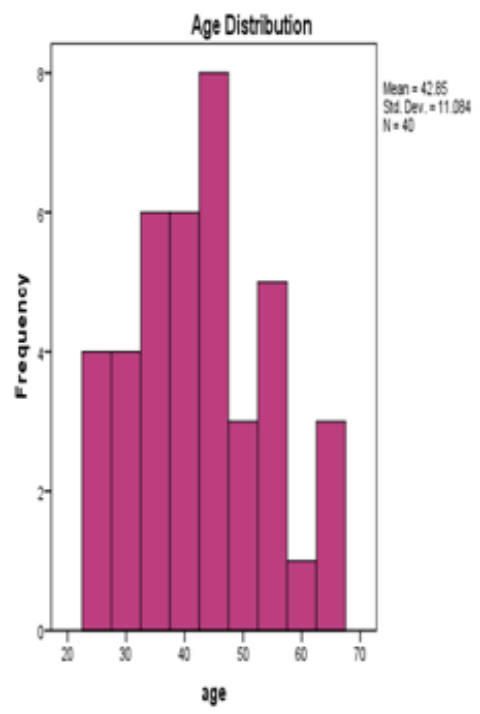

sex

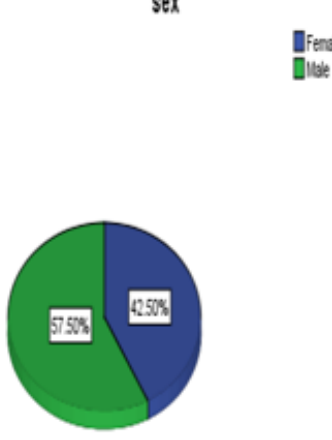


Table2: Table showing Descriptive statistics of Drugs lignocaine(Drug A) \& Ondansetron (Drug B).

\begin{tabular}{|l|l|l|}
\hline \multirow{2}{*}{ DRUG A } & Median & 2 \\
\cline { 2 - 3 } & IQR & 1 \\
\hline \multirow{2}{*}{ DRUG B } & Median & 2.50 \\
\cline { 2 - 3 } & IQR & 1 \\
\hline
\end{tabular}

*IQR=Interquartile range

Table3: Table showing Descriptive statistics for Pre-operative Parameters:

\begin{tabular}{|l|l|l|l|}
\hline Pre-operative & N & Mean & SD \\
\hline BP & 40 & $124.75 / 73.2500$ & $14.13987 / 9.71055$ \\
\hline HR & 40 & 67.0500 & 5.58363 \\
\hline SPO2 & 40 & $.9665(96.65 \%)$ & .01762 \\
\hline
\end{tabular}

Table4: Table showing Descriptive statistics for Post-operative Parameters:

\begin{tabular}{|l|l|l|l|}
\hline Post-Operative & N & Mean & SD \\
\hline BP & 40 & $125.25 / 73.00$ & $14.320 / 7.579$ \\
\hline HR & 40 & 72.5000 & 6.51232 \\
\hline SPO2 & 40 & $.9713(97.13 \%)$ & .01453 \\
\hline
\end{tabular}

$\mathrm{P}<.001$, therefore it is statistically significant, That is this study illustrates that ondansetron is better then lignocaine on prevention of injection pain caused by etomidate during induction of anesthesia.

\section{Discussion}

Etomidate is a well-known substituted imidazole induction agent that shares most of the beneficial characteristics of propofol as (rapid onset/offset and minimal residual sedation) and is also associated with a very high degree of hemodynamic stability [7-9]. Although etomidate cause adrenocortical suppression, a single injection which is used to induce anaesthesia will only produce a transient and clinically insignificant interference with adrenocortical function. Because of its Hemodynamic stability it is preferred agent to induce anaesthesia in patients with ischemic heart disease, valvular heart disease, patients with cardiomyopathy and with any patients with poor ventricular function [5-8]. However, its use is limited by two major side effects, pain on injection and involuntary movements [14-15]. Patients are unaware of the involuntary movements, which do not appear to cause any sequel; but pain on injection is distressing to the patient, so it is a major disadvantage. Although the underlying mechanism is still not fully understood, the explanation for the pain included endothelial irritation, osmolality differences, unphysiological $\mathrm{pH}$ and the activation of mediators. The initial component of pain, involving immediate stimulation of nociceptors and free nerve endings seems to be associated mainly with the concentration of free drugs within the aqueous phase of the emulsion. The delayed component of pain appearing within half a minute, is also believed to result from interaction with nociceptors and free nerve endings; however, promoted by local vasodilatation and hyper permeability induced by bradykinins possibly also prostaglandin E2[11-13]. Pain on injection is reduced by using large veins, various agents to etomidate solutions and changing the etomidate formulations, Pre treatment with a small dose of lignocaine, opiates, non steroidal anti-inflammatory drugs, ketamine, esmolol/metoprolol, magnesium, clonidine/ephedrine combination, dexamethasone, and metoclopramide, all have been tested with variable efficacy[11,15]. Ondansetron which is a commonly used drug to prevent Post operative nausea and vomiting is shown to be effective in preventing the pain of propofol Injection. If Ondansetron is effective in reducing the pain of etomidate injection, the we can avoid other drug which is exclusively used to prevent pain of etomidate injection and thereby we can avoid any adverse effect of that drug. This study shows pre treatment with lignocaine $1 \%$ gives better pain relief when compared to ondansetron.

\section{Conclusion}

This study illustrates that lignocaine is better then ondansetron on preventation of injection pain caused by etomidate during induction of anesthesia

\section{References}

[1]. Brown PM, Moss E. Reduction of pain on injection of etomidate. Anaesthesia 1981;36:814-6.

[2]. Corssen G, Reves J, Stanley T. Dissociative anesthesia. Intravenous Anesthesia and Analgesia. Philadelphia: L ea and Febiger; 1988. p. 99.

[3]. Levins T. Etomidate in procedural sedation. Air Med J. 2011; 30:45---8.

[4]. Doenicke AW, Roizen MF, Hoernecke R, et al. Solvent for etomidate may cause pain and adverse effects. Br J Anaesth. 1999; 83:464---6.

[5]. Bovill JG. Intravenous anesthesia for the patient with left ventricular dysfunction. Semin Cardiothoracic Vasc Anesth.

[6]. Singh R, Choudhury M, Kapoor PM, Kiran U. A randomized trial of anesthetic induction agents in patients with coronary artery disease and left ventricular dysfunction. Ann Card Anaesth. 2010;13(3):217-23. 
[7]. Guzelmeric F, Erdogan, H. B., Kocak, T. . Anesthesiologic approach to cardiac emergencies. Turk J of Thoracic Cardiovascular Surgery. 2007; 15:82-9.

[8]. Reiz S, Balfors E, Friedman A, Haggmark S, Peter T. Effects of thiopentone on cardiac performance, coronary hemodynamics and myocardial oxygen consumption in chronic ischemic heart disease. Acta Anaesthesiol Scand. 1981;25(2):103-10. 10. Stephan H, Sonntag H, Schenk HD, Kettler D, K

[9]. McCollum JS, Dundee JW. Comparison of induction characteristics of four intravenous anaesthetic agents. Anaesthesia. 1986; 41:995---1000

[10]. Wilde MI, Markham A. Ondansetron --- a review of its pharmacology and preliminary clinical findings in novel applications. Drugs. 1996; 52:773---94.

[11]. Haus U, Spath M, Farber L. Spectrum of use and tolerability of 5-HT3 receptor antagonists. Scand J Rheumatol Suppl.2004; 119:12---8.

[12]. Gregory RE, Ettinger DS. 5 HT3 receptor antagonists for the prevention of chemotherapy -induced nausea and vomiting. A comparison of their pharmacology and clinical efficacy. Drugs. 1998; 55:173---89.

[13]. Barann M, Gothert M, Fink K, et al. Inhibition by anaesthetics of 14C-guanidinium flux through the voltage-gated sodium channel

[14]. Hynynem M, korttila K, Tammisto T. Pain on iv injection of propofol (ICI35868) in emulsion formulation: short communication. ActaAnaesthesiolscand 1985; 29:651-2.

[15]. King SY, Davis FM, Wells JE, Murchinson DJ, pryorPJ.lidocaine for the prevention of pain due to injection of etomidate. AnesthAnalg 1992;74:246-9.

[16]. McCrirrick A, Hunter S. pain on injection of etomidate : the effect of injection temperature . Anaesthesia 1990; 45:443-4. 6. Sokes DN, Robson N, Hutton P. Effect of diluting etomidatel on the incidence of pain on injection and venous sequelae . Br $\mathrm{J}$ Anaesth $1989 ; 62$

[17]. Mcculloch MJ, Less NW. Assessment and modification of pain on injection with etomidate.Anaesthesia 1985;40:117-20.

[18]. Ambesh SP,Dubey PK,Sinha Pk. Ondansetron pre-treatment to alleviate pain on etomidatel injection : A randomized , controlled , double - blind study AnesthAnalg 1999

[19]. Vanacker B, Wiebalck A, Van Aken H, Sermeus L, Bouillon R, Amery A. Quality of induction and adrenocortical function: a clinical comparison of Etomidate-Lipuro and Hypnomidate. Anaesthesist 1993; 42: 81-99

[20]. Fragen RJ, Shanks CA, Molteni A, Avram MJ. Effects of etomidate on hormonal responses to surgical stress. Anesthesiology 1984; 61: 652-6

[21]. Schenarts CL, Burton JH, Riker RR. Adrenocortical dysfunction following etomidate induction in emergency department patients. Acad Emerg Med 2001; 8: 1-7 18 Mayer M, Doenicke A, Nebauer AE, Hepting L. Propofol and etomidate-Lipuro for induction of general anesthesia. 